Revista Complutense de Educación

ISSNe: 1988-2793

http://dx.doi.org/10.5209/RCED.64578

\title{
Didáctica de las matemáticas para maestros de Educación Infantil
}

Autor: Muñoz-Catalán, M.C. y Carrillo, J. (eds.)

Editorial: Madrid: Paraninfo.

Año de publicación: 2018

El manual se nutre de la Didáctica de las Matemáticas en una etapa, la Educación Infantil, que durante décadas no se ha considerado esencial en el aprendizaje de la disciplina; sin embargo, cada vez son más las investigaciones que están mostrando la importancia de un trabajo sólido en este periodo escolar, desde "la necesidad de unas matemáticas profundas y rigurosas" (p.1).

El manual recoge las aportaciones de diez autores, que coordinados por los profesores M. ${ }^{a}$ Cinta Muñoz-Catalán y José Carrillo, han conseguido una obra coherente, con un hilo claro en la estructura y de lectura agradable y distendida, que ilustra con imágenes sencillas aquellas situaciones cuya comprensión y aplicación podría ser más compleja.

El manual contiene nueve capítulos que pueden leerse de manera continua y que, al tiempo, tienen la suficiente solidez para que la lectura se haga desde aquella necesidad didáctica que el maestro y/o el formador de maestros pueda tener, porque para ellos está dirigido los maestros del aula, así como para aquellos futuros docentes que buscan comprender cómo es el aprendizaje del niño, creando actividades que respondan a las necesidades individuales y grupales.

La estructura del libro tiene un hilo progresivo en cuanto a la enseñanza.

Se inicia con la exposición del contenido desde la propia matemática, para después plantear los aspectos desde la perspectiva de su enseñanza y aprendizaje, considerando las recomendaciones internacionales.

Los contenidos comienzan con el número natural, base de los siguientes cuatro capítulos, conceptualizado desde su construcción y como instrumento de conteo y operaciones, se aborda desde su aprendizaje en los bloques de contenido de la medida y el análisis de los datos. Para mostrar cómo el niño percibe el espacio, se muestran dos capítulos fundamentales para ayudar al infante a interpretar y representar el entorno que le rodea, prestando especial atención a formalizar las figuras y cuerpos geométricos. Los dos últimos capítulos, más generales, sostienen una propuesta de qué y cómo se debe manejar el pensamiento lógico y las formas de razonamiento para su enseñanza en esta etapa. El último capítulo está elaborado desde la práctica de enseñanza en la etapa, por lo que puede resultar especialmente interesante para la formación inicial.

El manual parte de un diseño del currículo serio y fundamentado, que habrá de desarrollarse en cada escuela de manera particularizada adaptándose a cada contexto y ser de utilidad para todo niño. La práctica matemática debe mostrarse desde distintas perspectivas como formas de hacer diversas; conviene partir de la relación entre 
las representaciones que dé sentido y necesidad de aprender al niño, al tiempo que el maestro sabe guiar de manera razonada el trabajo.

Pongamos como ejemplo algo que puede parecer tan simple como "restar cuatro menos tres" (p. 16); esta situación, fundamentada en una operación, da lugar a un abanico de formas de mostrársela al niño, que van desde el símbolo matemático a la situación real pasando por el modelo manipulativo. Para cada uno de ellos, el maestro debe contar con conocimientos de la estructura aditiva que fundamenta la operación o de los materiales que pueden ser de utilidad y los que no. Resulta por ello el manual de interés especial para aquellos aprendices de maestro, que se inician en esta tarea de la enseñanza.

Encontramos capítulos o epígrafes que parten de cómo el niño aprende para desarrollar sugerencias desde la didáctica de la matemática. Por ejemplo, cuando se habla de la magnitud tiempo, sabiendo de la dificultad de comprensión que tiene el niño, por ser una magnitud no perceptible como la longitud. Así, el epígrafe parte de la acción del niño, haciendo que el niño tome conciencia de ritmos y repeticiones temporales (p. 169), desde su registro y comprensión.

Para abordar el número, el niño ha de realizar un trabajo previo "partiendo de la seriación y clasificación" (p. 21) que le facilite su necesidad, comprensión y manejo posterior. Partir de la experiencia del niño desde su percepción a la interpretación que hace del número, puede ayudar al maestro a determinar el itinerario a seguir para trabajar distintos tipos y utilidades de los números, tanto desde la naturaleza ordinal como cardinal. Uno de los materiales que se expone de manera detallada en este punto son las regletas de Cuisenaire, "por su relación con los números" (p.70).

El número puede servir de base también para el trabajo con la resolución de problemas, metodología fundamental en la enseñanza de las matemáticas. El maestro debe conocer no únicamente los tipos de problemas sino la fundamentación teórica que da lugar a cada uno de ellos, para que el trabajo en el aula sea progresivo, adaptándose a los niveles de desarrollo (modelización, conteo y hechos numéricos), dando lugar así a un proceso sólido en cuanto a la adaptación y por tanto al aprendizaje.

El espacio se muestra desde las características y tipos (vivido, percibido y concebido), haciendo que el niño mire su entorno de una manera comprensiva, desde la incorporación en el aula de los materiales adecuados (p. 226).

El manual finaliza con dos capítulos sustentados en el razonamiento matemático y la práctica en el aula, que dan lugar a un cierre reflexivo y necesario para el maestro que va a desarrollar su práctica de enseñanza de las matemáticas en Educación Infantil.

Arteaga-Martínez, B. Universidad de Alcalá 